\title{
AVALIAÇÃO DO TREINAMENTO MENTAL NA MELHORA DE DESEMPENHO DO SAQUE NO VOLEIBOL
}

\author{
José Maria Montiel \\ Psicólogo, Especialista em Diagnóstico e Triagem, Mestre e Doutor em Avaliação Psicológica em \\ Contexto de Saúde Mental pela Universidade São Francisco. Pesquisador colaborador do \\ Laboratório de Psicodiagnóstico e Neurociências Cognitivas (LaPENC) - Unisal - Americana. \\ Atualmente é Professor do Centro Universitário FIEO - UNIFIEO/SP - Programa de Pós-Graduação \\ Strictu Sensu em Psicologia Educacional - Fundação Instituto de Ensino para Osasco.
}

Daniel Bartholomeu

Psicólogo, Mestre e Doutor em Avaliação Psicológica em Contexto de Saúde Mental pela Universidade São Francisco. É colaborador do Laboratório de Pesquisa em Psicologia do Esporte (Lepespe) e coordenador do Laboratório de Psicodiagnóstico e Neurociências Cognitivas (LaPeNC). Atualmente leciona no Centro Universitário Salesiano de Americana.

Heitor Francisco Pinto Cozza

Possui graduação em Psicologia pelo Centro Universitário de Santo André mestrado em Avaliação Psicológica em Contextos de Saúde Mental. Doutor em Psicologia (Avaliação Psicológica em Contextos de Saúde Mental) pela Universidade São Francisco. Tem experiência na área de Psicologia do Esporte, atuando em clubes do interior do estado de São Paulo. Atua como docente do UniA, Centro Universitário Anhanguera de Santo André.

Afonso Antonio Machado Licenciado em Educação Física (PUC); graduado em Filosofia e Pedagogia. Mestre e Doutor em Educação, pela UNICAMP. Pós-Doutorado pela Faculdade de Lisboa e na Universidade do Minho. Livre-docente pelo Instituto de Biociências, UNESP - Rio Claro. Professor adjunto da UNESP/ Rio

Claro. Coordena o LEPESPE (Laboratório de Estudos e Pesquisas em Psicologia do Esporte). Coordenador do Programa de Pós-graduação em Desenvolvimento Humano e Tecnologias (DEHUTE), no IB/UNESP - Rio Claro.

Juliana Francisca Cecato

Psicóloga, Bióloga pela Universidade São Francisco. Mestrado em Ciências da Saúde pela Faculdade de Medicina de Jundiaí, e Pós Graduanda em Psicopedagogia pela Anhanguera Educacional.

\begin{abstract}
Resumo
Este trabalho teve por objetivo investigar os efeitos do treinamento mental sobre a performance do saque de jogadores de voleibol. Participaram da pesquisa seis jogadores do sexo masculino, titulares de uma equipe de voleibol do interior do estado de São Paulo com idades entre 18 e 25 anos. Verificou-se o desempenho do saque em três campeonatos distintos numa mesma temporada. Os saques foram avaliados nas situações de jogo ao longo do processo de intervenção. As médias das medidas obtidas indicaram uma melhora do desempenho do saque no decorrer do experimento, com um aumento dos acertos e diminuição dos erros desde a linha de base ao final do processo de intervenção. Os erros diminuíram significativamente do início da intervenção ao final dela e do meio do processo ao final.

Palavras-chave: treinamento mental; voleibol; saque; psicologia do esporte.
\end{abstract}




\title{
ASSESSMENT OF MENTAL TRAINING IN IMPROVING PERFORMANCE SERVE IN VOLLEYBALL
}

\begin{abstract}
This article aimed to investigate the effects of mental training on volleyball players service performance. Six male volleyball players aged from 18 to 25 years old of a team from the interior of São Paulo's state were studied. The service performance was evaluated in three different championships of the same season. The services were scored in game situations at the same time of the intervention process. The measure means indicated service performance increased with the mental training practice, with more services performed correctly and less mistakes at the end of the intervention process. The mistakes dimished significantly from the baseline to the final of the intervention process and from the start of the intervention process to its final.

Keywords: mental training; volleyball; service; sport psychology.
\end{abstract}

\section{EVALUACIÓN DEL ENTRENAMIENTO MENTAL PARA MEJORAR EL RENDIMIENTO SIRVEN EN EL VOLEIBOL}

\begin{abstract}
Resumen
Este estudio tuvo como objetivo investigar los efectos del entrenamiento mental en el rendimiento de la bolsa de jugadores de voleibol. Los participantes fueron seis jugadores masculinos, con un equipo de voleibol en el estado de São Paulo, 18 y 25 años de edad. El servir fué avaliado en tres campeonatos diferentes en la misma temporada. Los dibujos se evaluaron en situaciones de juego en todo el proceso de intervención. Las medidas medias indicaron una mejora del rendimiento de saqueo durante el experimento, con un aumento de golpes y errores disminuyó desde el inicio hasta el final del proceso de intervención. Errores disminuyeron significativamente desde el inicio de la intervención en el extremo de la misma y el medio del proceso hasta el final.
\end{abstract}

Palabras clave: entrenamiento mental; voleibol; servicio; psicología del deporte.

\section{INTRODUÇÃO}

O voleibol é tido como um dos esportes de massa no Brasil, caracterizando-se como um fenômeno social esportivo, tanto quanto o futebol, derrubando a ideia que é um esporte elitista, caro e restrito somente a clubes sociais. Muitas empresas e outros organismos sociais diversos têm apoiado esse esporte, inclusive dando nomes de suas marcas às equipes que disputam as principais competições esportivas no país. Esta modalidade é um tipo de prática esportiva que combina diversos elementos a força, a rapidez e grande variação, por exemplo, no ataque além de uma forte marcação na rede (Beutelstahl, 1990). O fato de ser um esporte coletivo sem contato físico não diminui os aspectos de violência e intimidação, uma vez que em posições específicas de rede o atleta se depara com olhares e murmúrios dos adversários ou, ainda, em algumas ações de ataque ou de defesa são necessário conter (ou extravasar) a 
cólera que o momento esportivo emana (Bonnefoy, 2004). Tais elementos psicológicos encontram ecos diante das necessidades de uma atenção seletiva aprimorada, uma alta capacidade de antecipação de jogadas e um equilíbrio emocional bem ajustado, que facilitarão o desempenho cognitivo que imprimirá as interpretações acertadas e as ações adequadas para cada situação do jogo. Tais apontamentos fazem com que o trabalho de ensino e treinamento do voleibol seja muito especializado, dependente de características complexas e específicas, que depende essencialmente de seis jogadores e a forma como esses seis jogadores se dispõem na quadra determinam formas de ações particulares que vão desde um momento de "expectativa" para receber a bola e organizar o ataque, desencadeando movimentos rápidos e extremamente precisos, mantendo sua ordem interna e tentando desestabilizar a equipe contrária.

Essas situações de confronto provocam o que se denomina rally, ou seja, uma sequência de ações de jogadas desde o momento do toque do saque até a bola estar fora de jogo que gera situações que entram em um padrão "quase cíclico" de movimentos (Ivoilov, 2005). Assim, o sucesso de uma equipe sobre a outra é quebrar esse momento "quase cíclico" e, para desestabilizar o adversário, portanto, crê-se que a busca das ações imprevisíveis no vôlei é que torna uma equipe vencedora. Diferentemente de outros esportes de quadra, no jogo de voleibol a contagem se dá em todo momento em que o rally é finalizado. Isso marca muito o "erro" no voleibol. Errar implica não só na perda de posse de bola, mas também, na contagem de um ponto em favor do adversário. Esse reforço ao "erro" provoca um clima forte de "frustrações", isso implica que deve ser dada ao aspecto psicológico do jogo uma relativa importância. Sobretudo quando se está iniciando alguma criança nesta modalidade esportiva.

Analisando o jogo pelo ponto de vista da ação individual do jogador percebe-se que, uma vez que esse jogador cometeu "erro" no seu ato motor, não há como esse "erro" ser "acertado" pelo executante. Diferentemente, em um esporte como o basquete quando a bola escapa da mão de um driblador, existe ainda a possibilidade do mesmo consertar sua falha passando a bola a um companheiro de equipe (Beutelstahl, 1990; Gorski \& Krieter, 2003). No vôlei, se o levantador colocar a mão de forma inadequada ao tocar a bola, ele poderá cometer dois toques ou uma condução de bola, determinando que a ação seja interrompida ali, naquele momento de seu "erro". A posição de "expectativa" demanda competências motoras e mentais, envolvendo a concentração e a 
capacidade de antecipação. O movimento de armação de ataque, ataque e defesa demandam uma prontidão muscular extrema e ações musculares curtas e rápidas em que frações de segundos são decisivas para o êxito de um lance. A não "apreensão" da bola no momento das ações do jogo determina uma posição do corpo do jogador no espaço de jogo precisa e equilibrada, pois só assim a sua abordagem à bola será efetivamente correta, não dando margem a erros no momento de contato. Nesse processo, dois fundamentos sugerem melhores olhares: o saque e o ataque. Ambos, atualmente, configuram aquilo que há de mais agressivo e violento, no esporte, uma vez que estão sendo executados com muita velocidade e força. A precisão que cada um deles deve garantir apenas reflete o nível de habilidade do jogador executante (Ivoilov, 2001, 2005).

As atuais equipes mundiais de voleibol, masculino e feminino, apresentam um conjunto ofensivo que indica para uma especialidade suprema do fundamento, mas que ainda não chegou ao seu limite, uma vez que mais e mais possibilidades de ação podem surgir à medida que os ensinamentos vão se aprimorando (Bonnefoy \& Lahuppe, 2003; Lavega, 2005). Isso significa dizer que muito breve as jogadas de ataque serão acrescidas de novos detalhes que intensificarão o trabalho dos atletas de defesa. Por sua vez, o saque foi o fundamento que apenas iniciava um jogo, por um longo período de tempo. No entanto, a partir da década de 1980, ele assumiu a posição de um dos mais detalhados elementos a ser examinado, numa partida. Sua execução precisa, aliada a força e velocidade, ao iniciar um jogo, busca a marcação do primeiro ponto, acima de tudo. Até mesmo as equipes iniciantes já apresentam um saque bem trabalhado, que implique em dificuldades para a recepção do adversário, ou mesmo um "ace", que é o ponto direto, quando a bola atinge o solo sem ser recebida (Machado, 2006). Este fato faz com que exista um clima de desconforto e inquietação em momentos que antecedem o ato de sacar: tanto quem saca como quem recebe busca a concentração adequada para uma atuação regular.

A partir de 1994, a FIVB ao modificar o sistema de pontuações demonstrou que o saque possuía grande importância ofensiva na dinâmica do jogo de voleibol, dando forca ao rendimento, já que o erro seria revertido em ponto para o adversário. Essas modificações fizeram surgir à figura do líbero, função que, até então, não existia. Esse atleta é especialista em fundo de quadra, com funções de passe (recepção do saque) e defesa. Desse modo, o saque passou a ter uma influência notória e direta sobre a recepção e produzindo uma reação em 
cadeia às outras ações necessárias à construção do ataque, podendo modificar e diminuir a variação dos mesmos (tipos de ataques) em diferentes posições, aumentando sistematicamente o uso de bolas altas, ou seja, bolas de segurança (segunda bola) (Gerbrands \& Murphy, 1995; Fróhner \& Zimmermann, 1996). Com isso, cresceu também a necessidade de formar uma linha de passe com três receptores e até quatro passadores, como no feminino. Esses fatores confirmaram o saque como elemento chave do rendimento no voleibol. Essa mudança colaborou para a modificação da forma da execução do saque. Reinventado pelo Brasil nos anos 80, o saque em suspensão ("viagem ao fundo do mar") disseminou-se pelo mundo nos anos 90, como se pôde constatar no campeonato mundial de 1994 com 3\% de incremento de ações com êxito frente a $17 \%$ a mais de erros (Zimmermann, 1995). Esta tendência foi confirmada nos Jogos Olímpicos de Atlanta, onde a proporção de ações de saque em suspensão recebeu um aumento significativo de $25 \%$ em relação a 1992 e 50\% em relação a 1996 em comparação ao saque parado, assumindo, portanto, mais risco de erros, como também aumentando a possibilidade de ponto direto ou opções de bloqueio mais previsíveis com menos opções de ações de êxito de ataque, forçando mais o uso de bolas altas e de bolas do fundo (ataque atrás da linha dos três metros) (Fróhner \& Zimmerrmann, 1996; Gerbrands \& Murphy, 1995).

Seguindo os apontamentos anteriormente descritos em relação aos ajustamentos e modificações no ambiente do voleibol, outro aspecto relevante tem demonstrado crescimento que se refere aos planos de treinamentos as quais tem feito com que a modalidade seja fonte de numerosos estudos, os quais visam potencializar o rendimento dos atletas permitindo a visualização de detalhes e particularidades desta modalidade esportiva, sejam as encontradas no âmbito técnico, tático e físico. Tais avanços têm permitido com que haja diferenciais no resultado final alcançado por uma equipe. Os avanços têm tornado 0 jogo altamente competitivo onde os atletas se aperfeiçoem constantemente, tanto a nível físico, quanto psicológicos, ou especificamente mecanismos neurais sejam envolvidos na percepção e identificação das ações motoras individuais como de seus adversários, assim servindo de base para um melhor desempenho (Morales et al, 2009). Alguns estudos têm investigado tais aspectos em diferentes modalidades esportivas (Evans, Jones \& Mullen, 2004; Munroe, Giacobbi, Hall \& Weinberg, 2000; Cumming \& Hall, 2002; Calmels, Berthoumieux \& d'Arripe-Longueville, 2004). 
Em um apontamento significativo investigando os efeitos de um "pacote" de treinamento mental sobre a performance de corredores de 1600 metros, Patrick e Hrycaiko (1998) estudaram três triatletas e um corredor de elite, todos do sexo masculino. Os participantes foram observados num primeiro momento para se obter uma linha de base e depois, nas fases da intervenção, introduzida quando se obteve estabilidade do desempenho dos indivíduos. Um dos participantes foi usado ainda como controle para avaliar possíveis efeitos do treinamento/prática. A estabilidade do desempenho na corrida foi avaliada por dois observadores que registraram o tempo feito por cada corredor na prova. Foi utilizado ainda um questionário para controlar quanto cada participante utilizou as habilidades mentais durante a prática da corrida. A intervenção incluiu técnicas de imagem mental, relaxamento, autoconversação para controlar pensamentos negativos e estabelecer outros positivos e finalmente, estabelecimento de expectativas de aquisição de resultados para cada treino. Cada sessão tinha 90 minutos e foi administrado treinamento por três dias. Os resultados apontaram que o pacote de treinamento mental foi efetivo na melhora da performance dos corredores. Ao mesmo tempo, todos os participantes aproveitaram o treinamento mental e relataram gostar dos resultados obtidos.

Por sua vez, Calmels, Berthoumieux e d'Arripe-Longueville (2004) examinaram a efetividade de um programa de treinamento mental na melhora da atenção seletiva de quatro jogadores da seleção nacional americana de softball. Um deles foi selecionado como controle e foi feita uma primeira avaliação de todos para a linha de base com o Test of Attentional and Interpersonal Style (TAIS). Cada uma das 28 sessões do programa durou 10 minutos e incluíam a imaginação de situações competitivas diversas. Os resultados demonstraram que o programa de treinamento em imaginação mental melhorou a habilidade dos jogadores de integrar estímulos externos, sem, no entanto, ficarem muito influenciados por eles, conseguindo direcionar a atenção mais adequadamente para os estímulos necessários, uma das facetas avaliadas pelo teste aplicado.

Como pôde ser percebido, ampliar a experimentação com realidades diferentes utilizando técnica de imaginação para o desportista não deixa de ser uma proposta interessante, enquanto prática que pode afetar o desempenho desses atletas. O processo de treinamento psicológico busca como um todo o equilíbrio emocional revertido em ações motoras acertadas. O treinamento 
mental, também conhecido por treinamento autógeno, visualização ou imagética, pode ser usado a movimentos específicos ou situações dentro de um contexto de um esporte qualquer. Essa "imaginação" apresenta-se de forma antecipatória (chegar antes, antever) ou retroativa (buscando seus melhores momentos para ações futuras) (Richardson \& Latuda, 1995). Para Eberspacher (1990), o treinamento mental seria a repetição planificada da imaginação consciente de uma ação de forma prática. Possui ainda três formas que são mais amplamente utilizadas, a saber: autoverbalização que consiste em repetir mentalmente o movimento; autoobservação, olhar para si próprio, observando os movimentos de uma perspectiva externa; e ideomotora que compreende antever sensações internas na execução do movimento. Desta maneira seria possível utilizar essa técnica para aprender, manter e aperfeiçoar as capacidades cognitivas para execução de movimentos através da imaginação, isto é, recriar uma experiência na mente. Assim, a imaginação compreenderia uma experiência sensorial que ocorreria na mente sem a participação do ambiente, sendo que para cada mudança fisiológica que ocorre no corpo existiria uma mudança paralela no estado emocional, portanto a imaginação, assim como experiências motoras, desencadeiam funções neurofisiológicas similares (Richardson \& Latuda, 1995; Eberspacher, 1990).

Em consonância, Schachter e Singer (1962) ressaltam que, quando uma pessoa pensa sobre um ato ou movimento de alguma parte do corpo, ocorre um aumento de registros eletromiográficos (atividade elétrica), correspondentes à localização. Destacam ainda a relação existente entre os processos cognitivos e a execução motora, principalmente quando se trata de táticas e estratégias, citando a descoberta de que as habilidades esportivas podem ser adquiridas ou mantidas no mesmo nível pelo treino mental. Tendo em vistas esses aspectos, os descritos anteriormente e a eficácia do treino mental em outras modalidades esportivas, nesse trabalho foram investigados os efeitos do treinamento mental sobre a performance do saque de jogadores de voleibol.

\section{MÉTODO}

\section{Participantes}

Foram estudados 13 jogadores de voleibol de um time profissional do estado de São Paulo que participaram de um programa de intervenção em Psicologia do Esporte. Desses, optou-se por manter somente aqueles que 
participaram de todas as partidas analisadas nas ocasiões estudadas, a saber, campeonato paulista, jogos abertos e liga nacional. Assim, restaram os seis jogadores do time titular, já que entre os demais (reservas) não houve regularidade na participação dos jogos nos eventos mencionados. As idades dos participantes variaram de 18 a 25 anos. Todos os jogadores eram do sexo masculino.

\section{Procedimento de Treinamento Mental}

Dentre as diversas formas de se estabelecer um treino mental, optou-se pelo treinamento mental autógeno. Esta técnica inicia-se com um relaxamento que consiste em uma série de frases elaboradas com a finalidade de induzir 0 sujeito a estados de relaxamento através de autossugestões sobre as sensações de peso e calor em suas extremidades, regulação das batidas de seu coração, sensações de tranquilidade e confiança em si mesmo e concentração passiva em sua respiração. A prática acontecia três vezes por semana em uma sala cedida pelo clube com colchonetes no chão para que os atletas pudessem deitar e relaxar e após os treinamentos físicos. Este relaxamento utiliza elementos de sugestão e criava espaço para a introdução da técnica de treino mental. Nesse, os atletas foram encorajados a mentalizar a prática do "saque viagem", visto que era o mais utilizado por eles, focando em cada um dos momentos do mesmo. Inicialmente, o peso da bola nas mãos, a visualização da quadra, a forma das mãos atirarem a bola para o alto, a rotação da bola no alto, o tempo de subida e descida da mesma, o momento certo do salto, a forma do salto, o posicionamento das pernas e braços, o ataque propriamente dito, a posição das mãos, o local em que se desejava colocar a bola na quadra adversária e a bola alcançando esse ponto. Em todas as situações propostas, propunha-se mentalizar sempre os acertos no saque.

\section{Procedimento de avaliação}

Verificou-se o desempenho do saque em três campeonatos distintos numa mesma temporada. Os saques foram avaliados nas situações de jogo no transcurso do próprio processo de intervenção para o aperfeiçoamento dessa técnica. Os dados foram coletados paralelamente a aquisição de conhecimento com o treinamento psicológico por meio da visualização. As pontuações atribuídas ao saque se deram de três formas distintas: positiva, quando o saque 
foi convertido em ponto direto; média, quando outro elemento do time, que não o levantador, levantou a bola ou quando o levantador levantou de manchete; e negativa quando ocorreram erros. Foram usados oito jogos de três campeonatos diferentes seguidos em ordem sequencial cronológica de A - campeonato paulista (junho-setembro), B - jogos abertos (outubro), e C - superliga nacional (dezembro-abril). No primeiro não houve apoio do treinamento mental, sendo introduzida essa técnica somente nos jogos abertos, momento em que houve o início do aprendizado da técnica. Na superliga, os atletas já estavam plenamente interados da técnica de visualização e a praticavam todos os dias da semana. Os sujeitos não foram informados da motivação da pesquisa com intuito de não causar uma nova variável, sendo comunicado que as técnicas seriam somente para melhorar o rendimento. Ao final da temporada, os jogadores foram questionados quanto ao uso dessas informações para uma pesquisa para as formalizações éticas e concordaram. Foi computado, para cada atleta, o total de pontos cometidos por saque, total de erros, total de bolas que foram efetivas no sentido de se dificultar a primeira bola (meios acertos) e o total de saques efetuados somando-se esses dados de todas as partidas referentes a cada campeonato. Assim, obtiveram-se essas medidas mencionadas por campeonato e estabeleceu-se uma proporção de acertos, erros e meios acertos, levando-se em conta o número de saques efetuados em cada campeonato por cada jogador.

\section{RESULTADOS}

Os resultados da análise descritiva da proporção dos acertos, erros e jogadas que impossibilitaram um ataque eficiente do time adversário (meios acertos) nos três campeonatos avaliados no decorrer da intervenção estão apresentados na Tabela 1. Os coeficientes de Skewnesse e Curtose indicaram que a medida de proporção de meios acertos no campeonato paulista não apresentou assimetria e muita dispersão ao redor da média, uma vez que estiveram mais próximos de 0 . Nas demais medidas, a assimetria e dispersão das curvas normais foram grandes, não se aproximando de uma distribuição normal de dados. Pese a isso o número reduzido de sujeitos da amostra, optouse por empregar provas não-paramétricas na análise de comparação dessas medidas. Tanto as pontuações máximas como as médias dos acertos aumentaram do campeonato paulista para os jogos abertos e desse para a superliga, indicando uma melhora do saque do time do início, antes da 
ocorrência do treino mental e ao final, com término do processo de intervenção, quando os jogadores já apresentavam bastante prática nesta técnica. Entretanto, pôde-se observar que houve uma grande dispersão no campeonato paulista e na liga. Isso parece indicar que, em relação ao início do processo de intervenção, houve uma melhora na performance do saque, mas a quantidade de aprendizagem dos jogadores variou bastante. Isso é reforçado ainda ao se observar que na liga, houve jogadores que não acertaram nenhum saque (pontuação mínima obtida), enquanto a pontuação máxima de acertos foi também a maior nesse campeonato em detrimento dos demais.

Tabela 1.

Estatísticas para a proporção dos Acertos, Erros e Meio acertos nos três campeonatos avaliados no decorrer da intervenção $(N=6)$.

\begin{tabular}{ccccccc}
\hline & Mínimo & Máximo & Média & DP & Skewness & Kurtosis \\
\hline $\begin{array}{c}\text { proporção meio } \\
\text { paulista }\end{array}$ & 32,00 & 53,96 & 40,69 & 8,32 & 0,77 & $-0,27$ \\
$\begin{array}{c}\text { proporção meio } \\
\text { aberto }\end{array}$ & 26,66 & 49,38 & 40,72 & 7,93 & $-1,16$ & 1,90 \\
$\begin{array}{c}\text { proporção de meio } \\
\quad \text { liga }\end{array}$ & 20,00 & 100,00 & 41,50 & 29,75 & 2,07 & 4,53 \\
$\begin{array}{c}\text { proporção erro } \\
\text { paulista }\end{array}$ & 14,28 & 66,66 & 31,79 & 18,04 & 1,86 & 4,19 \\
$\begin{array}{c}\text { proporção erro } \\
\text { aberto }\end{array}$ & 14,81 & 60,00 & 29,43 & 15,75 & 1,91 & 4,24 \\
$\begin{array}{c}\text { proporção de erro } \\
\quad \text { liga }\end{array}$ & 0,00 & 21,42 & 15,37 & 7,93 & $-1,95$ & 4,02 \\
$\begin{array}{c}\text { proporção acerto } \\
\text { paulista }\end{array}$ & 0,00 & 37,33 & 27,50 & 14,21 & $-1,95$ & 3,91 \\
$\begin{array}{c}\text { proporção acerto } \\
\text { aberto }\end{array}$ & 13,33 & 46,66 & 33,16 & 10,92 & $-1,22$ & 3,00 \\
$\begin{array}{c}\text { proporção de acerto } \\
\text { liga }\end{array}$ & 0,00 & 60,00 & 43,12 & 22,01 & $-2,03$ & 4,40 \\
\hline
\end{tabular}

Em relação à média dos erros, bem como sua pontuação máxima, observou-se uma queda do paulista para o aberto e deste para a liga, sugerindo uma diminuição ao longo do processo interventivo. Vale destacar que, comparando-se o campeonato paulista com a liga, os erros caíram pela metade. A variabilidade desses se manteve mais estável nos dois primeiros momentos e aumentou na Superliga, indicando bastante dispersão dos erros, da mesma forma que os acertos. Vale ressaltar que esse alto desvio-padrão evidenciado nas medidas decorre do número reduzido de sujeitos na amostra e de um desempenho bastante variado dos mesmos. Por fim, quanto aos meios acertos, 
evidenciou-se um aumento em sua média de proporções com o início da intervenção nos jogos abertos assim como na superliga. Além disso, sua pontuação máxima foi menor nos jogos abertos que no paulista e maior na liga em comparação aos demais momentos. A variabilidade também foi grande somente na liga, sugerindo uma maior dispersão em relação à proporção média dos meios acertos nesse campeonato. Além disso, a diferença entre a pontuação mínima e máxima foi maior nessa situação que nas demais, havendo jogadores que erraram muito esse tipo de jogada e outros com taxa de acerto bastante elevada. Na Tabela 2, estão as porcentagens totais de acertos, meios acertos e erros nos três campeonatos estudados ao longo do processo de intervenção.

Tabela 2.

Porcentagens de acertos, meios acertos e erros nos três campeonatos $(N=6)$.

\begin{tabular}{ccccccccc}
\hline \multicolumn{2}{c}{ Campeonato Paulista } & \multicolumn{3}{c}{ Jogos Abertos } & \multicolumn{3}{c}{ Superliga Nacional } \\
\hline+ & $\sim$ & - & + & $\sim$ & - & + & $\sim$ & - \\
\hline $29,5 \%$ & $49,7 \%$ & $20,8 \%$ & $33,0 \%$ & $46,9 \%$ & $20,1 \%$ & $48,4 \%$ & $37,0 \%$ & $14,6 \%$ \\
\hline
\end{tabular}

Como se pode verificar, a porcentagem de acertos aumenta ligeiramente do campeonato paulista, em que não havia prática de treino mental, para os abertos, quando do início da prática dessa técnica, sendo que na superliga o aumento dessa porcentagem é ainda maior, chegando a quase $50 \%$ de pontos diretos em saque, o que parece sugerir que a introdução do treinamento mental melhorou a eficiência do saque dos jogadores. Isso também é evidenciado ao se verificar a diminuição da porcentagem dos erros nos três campeonatos. Também os meios acertos diminuíram nessas condições. As diferenças já mencionadas nas proporções de acertos, erros e meios acertos nos três momentos de avaliação da intervenção foram testadas pela prova de Friedman para investigar se poderiam ser atribuídas ao acaso com intervalo de confiança de 5\%. Seus resultados não acusaram diferenças significativas para os acertos $\left(X^{2}=4,33\right.$; $p=0,142)$; e para os meios acertos $\left(X^{2}=4,00 ; p=0,185\right)$. Já os erros indicaram diferença significativa nas três situações $\left(X^{2}=7,00 ; p=0,029\right)$.

Foram investigadas ainda as diferenças de um campeonato ao outro, aos pares, das proporções de erros, acertos e meios acertos por meio da prova de Wilcoxon, estabelecendo-se nível de significância de 0,05. Os resultados dessa análise estão na Tabela 3. Por esses dados, evidenciou-se que a proporção de erros diminuiu significativamente do campeonato paulista (quando não havia 
iniciado ainda a intervenção) para a superliga (ao final do processo), assim como dos jogos abertos para a superliga. Os acertos e meios acertos não forneceram diferenças significativas nas situações estudadas, embora a tendência a aumentarem com o decorrer do treinamento mental tenha sido identificada na análise descritiva, sugerindo também mais acertos ao final do processo.

Tabela 3.

Resultados de Qui-Quadrado e níveis de significância da prova de Wilcoxon $(\mathrm{N}=6)$.

\begin{tabular}{|c|c|c|c|c|c|c|c|c|c|}
\hline & $\begin{array}{c}\text { proporção } \\
\text { meio } \\
\text { aberto - } \\
\text { proporção } \\
\text { meio } \\
\text { paulista }\end{array}$ & $\begin{array}{c}\text { proporção } \\
\text { de meio } \\
\text { liga - } \\
\text { proporção } \\
\text { meio } \\
\text { paulista }\end{array}$ & $\begin{array}{c}\text { proporção } \\
\text { de meio } \\
\text { liga - } \\
\text { proporção } \\
\text { meio } \\
\text { aberto }\end{array}$ & $\begin{array}{c}\text { proporção } \\
\text { erro } \\
\text { aberto - } \\
\text { proporção } \\
\text { erro } \\
\text { paulista }\end{array}$ & $\begin{array}{c}\text { proporção } \\
\text { de erro } \\
\text { liga - } \\
\text { proporção } \\
\text { erro } \\
\text { paulista }\end{array}$ & $\begin{array}{c}\text { proporção } \\
\text { de erro } \\
\text { liga - } \\
\text { proporção } \\
\text { erro } \\
\text { aberto }\end{array}$ & $\begin{array}{l}\text { proporção } \\
\text { acerti } \\
\text { aberto - } \\
\text { proporção } \\
\text { acerto } \\
\text { paulista }\end{array}$ & $\begin{array}{l}\text { proporção } \\
\text { de acerto } \\
\text { liga - } \\
\text { proporção } \\
\text { acerto } \\
\text { paulista }\end{array}$ & $\begin{array}{c}\text { proporção } \\
\text { de acerto } \\
\text { liga - } \\
\text { proporção } \\
\text { acerti } \\
\text { aberto }\end{array}$ \\
\hline$Z$ & $-0,11$ & $-0,94$ & $-0,94$ & $-0,11$ & $-1,99$ & &,- 094 & & $-1,78$ \\
\hline$P$ & 0,917 & 0,345 & 0,345 & 0,917 & 0,046 & 0,028 & 0,345 & 0,249 & 0,075 \\
\hline
\end{tabular}

Desse modo, a proporção de erros de saque diminuiu desde a linha de base, no campeonato paulista, em relação ao segundo momento de coleta de informações, os jogos abertos quando se iniciou a intervenção com o treinamento mental, diminuindo ainda mais ao final do processo interventivo na superliga. Nesses termos, a intervenção parece ter sido eficaz na melhora da performance do saque dos jogadores estudados. Procurou-se ainda analisar o desempenho individual dos sujeitos nos três campeonatos. Esses resultados estão sumariados nas Figuras 1, 2 e 3, apresentando os acertos, meios acertos e erros respectivamente. 


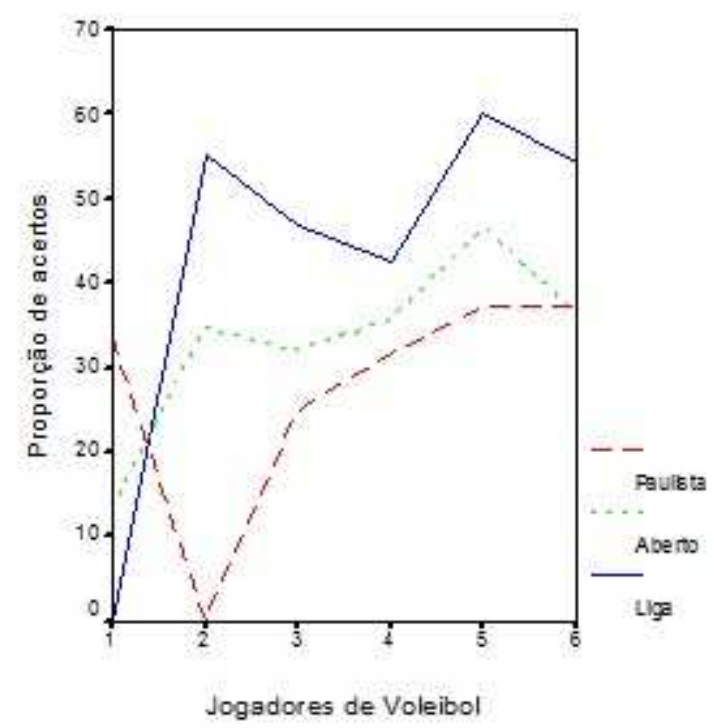

Figura 1. Proporção de acertos por participante nos três campe onatos estudados $(N=6)$.

Conforme se pode observar na Figura 1, para o sujeito 10 treinamento mental teve, aparentemente, um efeito inverso, já que no campeonato paulista, a proporção de acertos no saque foi maior e diminuiu nos jogos abertos e superliga respectivamente, momentos em que foi inserida e desenvolvida a intervenção. Para o jogador 6 o desempenho no saque foi igual na linha de base e no início da prática e só melhorou na liga. O restante dos participantes obteve performance semelhante, com uma baixa proporção de acertos no paulista, aumentando um pouco nos abertos com o início da prática de mentalização e ainda mais ao final dessa intervenção. 


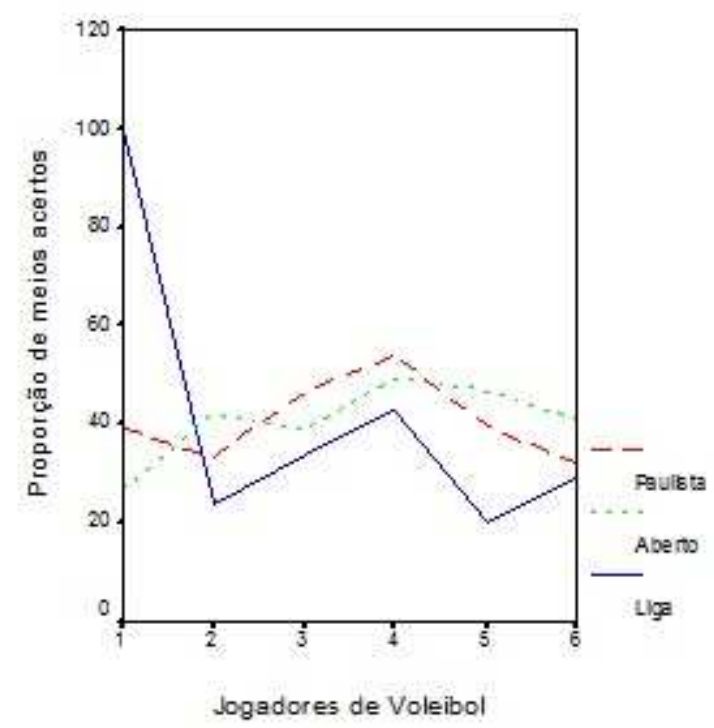

Figura 2. Proporção de meios acertos por participante nos três campeonatos estudados $(\Lambda=6)$.

Em relação aos meios acertos (Figura 2) o sujeito 1 obteve uma maior proporção desse tipo de saque na liga, seguida pelo campeonato paulista (linha de base) e dos jogos abertos quando do início do processo de intervenção. $\mathrm{Na}$ maior parte dos indivíduos, houve uma maior incidência de meios acertos em saque nos jogos abertos, quando iniciaram a prática da mentalização, sendo menor no paulista, quando não havia intervenção e diminuindo mais ainda na superliga. Esse fato é, de fato, esperado, já que ao final do tratamento os sujeitos deveriam acertar mais pontos diretos do que meios acertos, o que foi evidenciado. Os jogadores 3 e 4 tiveram maior proporção de meios acertos no paulista, depois nos abertos e na liga respectivamente. Em outros termos, com a intervenção os meios acertos que eram mais altos, diminuíram. 


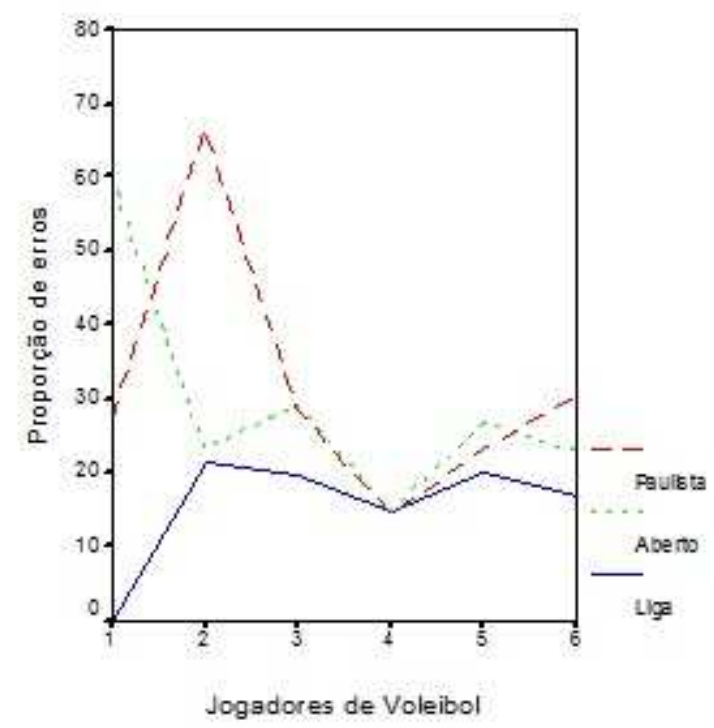

Figura 3. Proporção de erros por participante nos três campeonatos estudados $(N=6)$.

Por fim, foi analisado os erros individuais de cada atleta. Observando a Figura 3, evidenciou-se que os sujeitos 1 (que apresentou resultados diferenciados dos demais em todas as medidas do desempenho do saque) 5 e 3 , com o início do treino mental, aumentaram a proporção de erros (jogos abertos) diminuindo abaixo da taxa da linha de base ao final desse processo. No caso do participante 4, não houve alteração da proporção de erros de saque com a introdução da intervenção. Para os demais participantes houve uma diminuição do número de erros de saque da linha de base com o início da intervenção e ainda mais ao final desse processo.

\section{DISCUSSÃO}

Este estudo propôs a investigação da eficácia do treino mental autógeno sobre o desempenho do saque de jogadores de voleibol, com base na existência de uma relação entre os processos cognitivos e os atos motores, evidenciada pela literatura que descrevem, por exemplo, aumento de registros eletromiográficos quando pessoas pensam sobre atos ou movimentos de partes do corpo. Atrelado a isso, especificamente com o treinamento mental no esporte, inúmeras pesquisas identificaram sua eficácia em modalidades diversas. Nesse contexto, Mikes (1987) evidenciou o mesmo percentual de melhora do desempenho para os grupos com prática mental ou efetiva do lance livre em comparação ao grupo controle que treinava regularmente. Em outra descrição Patrick e Hrycaiko (1998) estudaram os efeitos do treino mental sobre o 
desempenho de corredores de 1600 metros, os resultados indicaram que o treinamento mental melhorou a performance dos corredores. Tais estudos apontam uma melhora nas habilidades atencionais dos jogadores/praticantes, já que integraram mais os estímulos externos e direcionaram a atenção mais satisfatoriamente aos estímulos pertinentes e que se bem executado, tende a afetar diretamente o desempenho, aumentando a eficácia do atleta (Frohner \& Zimmermann, 1996; Gerbrands \& Murphy, 1995).

Seguindo os objetivos deste estudo, as médias das medidas obtidas indicaram uma melhora do desempenho do saque no decorrer do experimento, com um aumento dos acertos e diminuição dos erros desde a linha de base, passando pelo início do emprego da técnica e ao final do processo de intervenção. Os meios acertos evidenciaram uma diminuição de porcentagem ao longo do processo, mas, considerando as suas proporções (em relação ao número de saques efetuados em cada uma das competições) observou-se um aumento. De fato, pode ter havido equívocos na avaliação desse tipo de jogada, já que é mais difícil de observar em comparação a erros de saque ou pontos diretos, sendo essa uma limitação desse trabalho. Analisando-se a significância estatística dessas medidas de desempenho nas três situações, identificou-se que somente os erros cumpriram esse critério. Mais especificamente, os erros diminuíram do campeonato paulista em relação à liga e dos jogos abertos para a superliga, não havendo diferenças significativas entre os jogos abertos (início da técnica) e o paulista (linha de base). Assim, pode-se sugerir que o treinamento mental ficaria realmente eficaz após um tempo de prática, não apresentando resultados imediatos de melhora da performance, o que corrobora os achados de Mikes (1987).

Por meio do desempenho individual dos atletas, evidenciou-se que, embora a maioria deles tenha seguido o padrão já mencionado de diminuição de erros e aumento de acertos no saque, houve participantes que destoaram em cada uma das avaliações feitas, sendo que, para um deles, (participante 1), o treino mental teve um efeito bastante diferente dos demais. Tais apontamentos se correlacionam com Marques e Gomes (2006), que indicam um efeito particularmente positivo sobre a capacidade dos atletas anteciparem e prepararem o tipo de ações e movimentações realizadas durante as competições e seu desempenho. 


\section{CONSIDERAÇÕES FINAIS}

Este estudo demonstrou a eficácia do treino mental autógeno sobre a performance do saque de jogadores de voleibol. Outros estudos com amostras maiores poderiam ser realizados no sentido de se reafirmar os dados obtidos e poderiam investigar as diferentes interpretações dos atletas do uso do treino mental com vistas a identificar pontos fortes e fracos da técnica, bem como a própria adequação dos mesmos neste tipo de técnica. Os resultados acima descritos apontam ainda na direção de que o ensino de outras habilidades necessárias ao jogo neste caso o voleibol, ou mesmo de outras modalidades esportivas, pode ser facilitado com o auxílio de técnicas dessa natureza. Cabe reforçar o descrito anteriormente em relação aos cuidados a possíveis problemas na avaliação desta população, especialmente na observação durante o desenvolvimento da atividade, bem como no tempo de pratica do treino mental, uma vez que é descrito como preditor para um melhor desempenho.

\section{REFERÊNCIAS}

Beutelstahl, D. (1990). Volleyball: Playing to win. New York: Arco Publ.Company. Bonnefoy, G \& Lahuppe, H. E N. R. (2003). Voleibol para jugar en equipo. Madrid: Inde.

Bonnefoy, G. (2004). Enseñar voleibol. Madrid: Inde.

Calmels, C., Berthoumieux, C., \& d'Arripe-Longueville, F. (2004). Effects of an imagery training program on selective attention of national softball players. The Sport Psychologist, 18, 272-296.

Cumming, J., \& Hall, C. (2002). Athletes' use of imagery in the off-season. The Sport Psychologist, 16, 160-172.

Eberspächer, H. (1990). Mentales Fertigkeitstraining. Sport Psychologie, 1, 5-13.

Evans, L., Jones, L., \& Mullen, R. (2004). An imagery intervention during the competitive season with an elite rugby union player. The Sport Psychologist, $18,252-271$.

Fróhner, B. \& Zimmermann, B. (1996). Select aspects of developments in men's volleyball. The Coach, 4(96), 12-13.

Gerbrands, T. \& Murphy, P. (1995). Las consecuencias del cambio de la regla de saque en el voleibol de sala. International Volley Teach, 1(95), 19-23.

Gorski, J. \& Krieter, U. (2003). Volleyball. München: Unisport.

Ivoilov, A. V. (2001). Volley-ball: Teach and learn. Paris: Vigot. 
Ivoilov, A. V. (2005). Vóleibol: Técnica, táctica, entrenamiento. Buenos Aires: Editorial Stadium.

Lavega, L. (2005). Juegos y formas jogadas de iniciación en el voleibol. Barcelona: Paidotribos.

Machado, A. A. (2006). Fundamentos básicos do voleibol. Rio de Janeiro: Guanabara Koogan.

Marques, A. \& Gomes, A. R. (2006). Avaliação da eficácia de um programa de treino de visualização mental num escalão de formação desportiva no basquetebol. Análise Psicológica, 24(4), 533-544.

Mikes, J. (1987). Basketball fundamentals: A complete mental training guide. Human Kinetics.

Morales, A. P., Azevedo, M. M. A., Maciel, R. N., Barcelos, J. L., Arêas Neto, N. T. \& Silva, V. F. (2009). Eficácia do processamento mental em jogadores de voleibol com níveis metacognitivos diferenciados. Revista da Educação Física, 20(1), 15-32.

Munroe, K. J., Giacobbi, P. R., Hall, C., \& Weinberg, R. (2000). The four Ws of imagery use: Where, when, why, and what. The Sport Psychologist, 14, 119-137.

Patrick, T., \& Hrycaiko, D. (1998). Effects of a mental training package on an endurance performance. The Sport Psychologist, 12, 283-299.

Richardson, P. A. \& Latuda, L. M. (1995). Therapeutic imagery and athletic injuries. Journal Athl Train, 30(1), 10-12.

Schachter, S. \& Singer, J. E. (1962). Cognitive, social and physiological determinants of emotional states. Psychological Review, 69, 379-399

Zimmermann, B. (1995). Principal evolución del voleibol masculino. Internacional Volley Tech, 1(95), 22-34.

Contato: d_bartholomeu@yahoo.com.br

Recebido em: 01/05/2013

Revisado em: 20/06/2013

Aceito em: 28/06/2013 